\title{
Succession Mediation in Europe
}

\author{
Judith Pfützenreuter
}

\section{The FOMENTO project}

Succession conflicts are characterised by a high degree of emotionality on the side of the parties in conflict. At the same time, legal questions play a great role.

The succession laws in every country are very different. If a succession case involves cross-border relations, such a case may become very complicated due to the different International Private Law regulations. The European Commission sought to counter this situation and elaborated the European Succession Regulation $^{1}$ in 2012.

To analyse the impact of this Succession Regulation and to show possible opportunities for mediation in the field of cross-border succession conflicts, the EUfunded project FOMENTO (Fostering Mediation in cross-border civil and succession conflicts) generated a research report, which has been recently published under the title: Mediation in cross-border succession conflicts and the effects of the 'Succession Regulation.'

The choice of which European countries to examine was made primarily on the basis of practical considerations. The project partners ${ }^{3}$ are from Germany, Italy and Poland and already availed of connections to Austria, France and Sweden. The six jurisdictions that thus emerged represent the major legal traditions on the European continent.

In the theoretical part of the study, the specific succession law systems in each of these six countries were described and the changes following implementation of the Succession Regulation were highlighted. This Regulation applies in every EUcountry (except Great Britain, Ireland and Denmark) as from August 2015. In addition, the current mediation systems of all six examined European countries were described.

In the second part of the study quantitative and qualitative data had been gathered to show real-life implications of the legal changes in these fields. The quantitative part, based on collected statistical figures and on an online survey with 752

1 Regulation (EU) No 650/2012 on jurisdiction, applicable law, recognition and enforcement of decisions and acceptance and enforcement of authentic instruments in matters of succession and on the creation of a European Certificate of Succession. Hereinafter referred to as the 'Succession Regulation'.

2 G. Barth, J. Barth, B. Böhm, J. Pfützenreuter, Mediation in cross-border succession conflicts and the effects of the 'Succession Regulation', 2018, www.fomentonet.eu/resources-type/projectoutputs. Following quotations are referring to this source.

3 Project partners are: Resolutia (Italy), Steinbeis Beratungszentren (Germany), Mediatorzy (Poland), Akademie für Mediation, Soziales und Recht an der Steinbeis Hochschule (Germany), Prodos Consulting (Italy). 
participants, underlines the increasing importance of cross-border succession cases. $^{4}$

For the qualitative part, 105 expert interviews with lawyers, notaries, judges and mediators have been conducted and analyzed. All experts are specialists in crossborder and/or succession cases. Most of the interviews have been conducted via telephone. Research questions behind the guideline-based expert interviews were:

- How far does the Succession Regulation pose new legal uncertainties and which uncertainties may open opportunities for the use of mediation as a conflict resolution method?

- What are the main obstacles and opportunities regarding mediation on succession matters in a cross-border context?

To this end, the peculiarities of succession cases, that have a cross-border context, have been examined from two different angles: from a legal point of view and from the perspective of interpersonal conflict matters. Of course, depending on their professional background, the interviewees can report more about their experience either in cross-border inheritance matters or in cross-border succession mediation.

Within the research and the project scope, succession cases with cross-border implications are defined as situations in which the heirs live in different countries (other than the successor) or the estate is located abroad. Cross-border mediation is likewise a structured conflict resolution method that is led by a neutral person who assists two or more conflicting parties, living in different countries, in trying to find a conflict solution that is in line with their individual interests and needs.

\section{Increasing importance of cross-border succession matters and Succession Regulation}

The collection of statistical data shows that the topic of cross-border succession matters is of increasing importance in European Union. The mobility amongst European citizens has increased in recent years. ${ }^{5}$

Within the online survey - where over 750 people had been reached - over $30 \%$ stated that there has been a succession case with a cross-border context in their private life. ${ }^{6}$

However, there are no clear figures about the frequency of cross-border succession cases. Therefore, the value of the estate that is transferred across borders can only be estimated. In any case, the analysis of statistical data shows that more and more people are and will be affected by heritages with some sort of international link. Be it because they themselves move to another (European) country or

4 The online survey was distributed over the internet and FOMENTO partner networks over a period of three months. The participants indicated their country of citizenship as follows: $39 \%$ Germany, 36\% Italy, 13\% Poland, 5\% France, 4\% Sweden, 2\% Austrian and 2\% other countries. See chapter 3.2: Statistics on the frequency of cross-border succession cases, and chapter 3.3: Outcome of the online survey.

5 See chapter 3.2: Statistics on the frequency of cross-border succession cases.

6 See chapter 3.3: Outcome online survey. 
because they inherit from relatives living abroad: citizens of the European Union are very likely to be confronted with questions about applicable inheritance law, especially regarding the consequences of the Succession Regulation.

The aim of the Succession Regulation was to facilitate the process of succession with international dimensions. Through the Regulation there have been huge changes, most importantly regarding the general jurisdiction: which court is competent for the succession case? Article 4 of the Succession Regulation provides the habitual residence of the deceased as connecting factor for jurisdiction in succession cases. This means the law applicable to the succession is the one of the country in which the deceased had his habitual residence at the time of death. Looking at the previous general jurisdiction in the countries examined, this means a change for all six countries. Until now, the decisive criterion was usually the nationality of the deceased.

The main advantage of the concept of habitual residence as connecting factor for determining the applicable law is that courts can usually apply the law of their own country (lex fori). This creates more legal certainty and predictability in court decisions. The main disadvantage, which was named by the experts and which can also be found in the literature, is that there is no uniform definition of habitual residence. There is room for interpretation which can lead in some cases to conflicts in terms of jurisdiction. How to decide, if someone has been working abroad for several years, but his or her family still lives in their home country? Some of the experts expressed their worries about possible misunderstandings and interpretation conflicts that could arise.

Yet, what has explicitly been highlighted as an advantage is the choice of law (Article 22 Succession Regulation). Through this possibility the successor can regain legal certainty. The interviewed professionals expressed their hope that through this legal instrument - choosing the law of one's nationality in one's testament - the number of planned heritages may increase. ${ }^{7}$

The main challenge at this point is to increase the awareness of the existence and the content of the Succession Regulation among European citizens. Even among the interviewed experts - who are all dealing with cross-border conflicts in succession cases - only three out of four had a certain knowledge about this Regulation (77 out of 105 experts did know about the Succession Regulation). ${ }^{8}$ Considering the changes which the Regulation brought about, an increased awareness is crucial. Especially regarding wills that have been drawn up before 17 August 2015 and to which the transitional regulations apply (Article 83 Succession Regulation)..$^{9}$ According to the experts, it is recommendable to seek advice in such situation and, if necessary, to draw up a new disposition of property. ${ }^{10}$ Many interviewed professionals have suggested more information campaigns about the Succession Regulation - especially for citizens that may be affected, such as immi-

7 See chapter 3.4.3: Advantages of the Succession Regulation.

8 See chapter 3.4.3.

9 See chapter 3.4.3: Transitional provisions.

10 See chapter 3.4.3: Choice of law. 
grants and students/workers/seniors who are living abroad. One goal of the FOMENTO project is to inform about the changes. ${ }^{11}$

\section{Mediation in cross-border inheritance conflicts}

In order to gain a deeper insight into the mediation systems in Europe, the effects of the Mediation Directive were presented in country reports. ${ }^{12}$ Due to the implementation of this Directive, in some countries a legislative process for mediation was initiated (e.g. Germany); in others the already existing mediation systems have undergone further development (e.g. Austria, Poland). The experts who were aware of the Mediation Directive did underline that the Directive did help to promote the idea and concept of mediation in general. ${ }^{13}$ Nevertheless, some of the interviewees criticized the Mediation Directive as being still too general and that its implementation varies widely across European countries.

The outcomes of all theoretical parts ${ }^{14}$ and of the qualitative interviews ${ }^{15}$ have been summarised, analysed and interpreted with regard to consequences for cross-border mediation in succession matters. The goal was to analyse the main internal strengths and weaknesses of mediation in cross-border disputes in succession matters, as well as external opportunities and obstacles which mediation is facing in this field. Some of the results will be presented here.

\section{Strengths of mediation in cross-border inheritance conflicts}

The professionals generally agreed that mediation is not only saving time and costs, but it also provides more satisfaction to clients. Mediation offers the unique opportunity for disputing parties to overcome communication problems and cultural differences, re-establish contact between them and bring them back around one table. Such interventions, on the level of human relations, with a focus on both parties' interests rather than on the legal situation only, provides outcomes which are generally more accepted by both sides and are therefore more satisfying and sustainable say the experts. ${ }^{16}$ Also they argued that mediation is highly appropriate for succession conflicts regarding the possibility to deal with strong emotions that can arise during the mourning process.

Furthermore, experts consider it as a significant advantage that mediation can be conducted even before somebody dies. ${ }^{17}$ This 'pre-mediation' can be seen as a family meeting with the future testator and his or her future heirs to make sure the envisaged allocation of shares in the future estate is accepted by everyone. According to the interviewed experts, that would be the best way to prevent con-

11 More information material and useful links about the Succession Regulation at: www. fomentonet.eu/

12 See chapter 2.1.

13 See chapter 3.4.10.

14 See chapter 2: Theoretical part.

15 See chapter 3.4: Qualitative Analysis of expert interviews.

16 See chapter 3.4.5: Cross-border mediation: advantages and challenges.

17 See chapter 3.4.9: When is a mediation useful in succession cases? 
flicts in inheritance matters. Of course, this is a very delicate matter to talk about. That is why this moderated process should be conducted by a professional, who is familiar with mediation tools and methods to determine the actual interests and feelings of the participants.

\section{Opportunities for mediation in cross-border inheritance conflicts}

Not only from an internal perspective (related to the characteristics of mediation) but also from an external (implications for legislation) perspective, several positive features of mediation in cross-border conflicts in succession matters can be identified: the institutionalization of mediation, several financial incentive systems as well as the professionalisation in mediation.

The national legislations on mediation (merely implementing the EU Mediation Directive or going beyond that) has contributed to the steady institutionalization of mediation in different ways, which also includes the standardization in terms of enforceability of settlements, the suspension of limitation periods and the duty of confidentiality.

A specific situation for mediation in succession cases can be seen in Italy. According to Italian law, mediation is compulsory in inheritance cases. That means that a first informative meeting with a mediator is a mandatory step before starting a lawsuit in inheritance matters. In addition, the Italian law also provides that mediators have to be registered at the Ministry of Justice. The law provides that in matters relating to inheritance, parties must engage a lawyer.

In other countries, like Sweden and Poland, there is the possibility of court-connected mediation, mostly carried out by judges. Nevertheless, it is also possible to conduct the mediation out of court. Unquestionably, this flexibility can be considered as a particular strength for the process of mediation.

Other opportunities for mediation in cross-border conflicts in succession matters arise from the respective financial incentive systems of the European countries.

In Austria, it is possible to get support for family and child disputes. ${ }^{18}$

In the case of Germany, the fact that mediation is generally offered by legal expense insurance policies contributes to an acceptance of mediation. The insurers also offer insurance policies that cover mediation, which fosters the demand for mediation. Apart from that, the legal basis in Germany increases the prestige of mediation by providing that the initiation of mediation suspends the statute of limitation. That means that if parties enter into mediation, the matters discussed will not be time barred. In succession matters, this involves two mandatory prescription terms: three years for a claim of property ( $\$ 2174 \mathrm{BGB})$, ten years for surrender of inheritance ( $\$ 2130$ BGB)). ${ }^{19}$

Also, in Germany, an evaluation report of the mediation law has been published in 2017. This report provides facts for the development of mediation and might foster the further use of mediation as a consequence of the increased level of awareness and indications for further development for the Federal Government.

18 See chapter 2.1.1: Mediation system in Austria: Institutional incentive system.

19 See chapter 2.1.3: Mediation system in Germany. 
In addition, mediations can be performed within private, state-recognised arbitration committees (Gütestellen) that ensure enforceability of mediation agreements as well as suspension of time limits. This may also be ensured by the inclusion of lawyers into the process, in particular when closing legal settlements ( $\S 794$ Nr. 4b ZPO). Yet, this is not the only feature that shows the opportunities provided by the flexibility that mediation models are offering. Such mediation techniques are also executed in court through so-called Güterichtermodell where judges are appointed as mediators if both parties agree on it. Concerning mediation training in Germany mediation associations are currently elaborating a joint organization, aiming for an introduction of higher quality standards than the minimum education and training standards established by German mediation law.

In addition, the Polish theoretical part has highlighted that the disadvantage of the slow juridical system in Poland can be turned into an advantage or, to be more precise, into an opportunity for mediation since that method of conflict resolution can be further promoted as a faster alternative method to be used in all kinds of conflicts.

One consequence of the Mediation Directive is the trend towards professionalisation in mediation. There is an increasing number of regulations on definition of mediation and the role of a mediator as well as processes to set up the minimum standards for mediation trainings. The formal requirements for mediators range from 'any natural person with a full capacity to perform acts in law and who enjoys full civil rights can become a mediator' in Sweden ${ }^{20}$ to 'the qualification required in view of the nature of the dispute or demonstrate', depending on the case, training or experience appropriate to the practice of mediation in France. ${ }^{21}$ The standardised minimum education level for mediators in some countries generally reinforces confidence in mediation as a tool for conflict resolution from a public perspective.

\section{Weaknesses of mediation in cross-border inheritance conflicts}

However, there are also several weaknesses of mediation in cross-border conflicts in succession matters that can be identified mainly from the statements of the interviewed experts.

First of all, it has to be recorded that, since mediation is institutionalised as a court-external conflict resolution process in almost every examined country, conflict parties who are unaware of its capabilities and existence, in case of doubt, continue to follow the procedural path. One of the main difficulties named by the interviewed mediators, is that there still is a lack of EU-citizens' knowledge of this alternative conflict resolution method. Especially in the field of succession is not particularly established and well-known yet. There are still misconceptions about the role and function of a mediator. The interviewed explained, for instance, that 
clients expect to get legal advice from the mediator or refuse to meet a lawyer for that purpose at all. ${ }^{22}$

Another issue mentioned in the interviews is the difficulty to identify experts, especially in cross-border cases. This draws the attention to the importance of networks at European level. Also, the need for cooperation between jurists and mediators had been highlighted during the interviews. ${ }^{23}$ Many of the experienced lawyers, notaries or mediators who work on cross-border cases explained that they already established a network of cooperation partners. This simplifies the process of handling cross-border cases enormously. ${ }^{24}$

In addition, many experts remarked that there is nothing that can be done when extremely quarrelling parties are not willing to take part in mediation. Mediation is a voluntary process and can be terminated by every conflict party at any time. Furthermore, there are some legal questions that need to be treated through court proceedings which cannot be mediated. ${ }^{25}$

\section{Threats of mediation in cross-border inheritance conflicts}

Apart from the internal issues mediation in cross-cross border conflicts is facing, there are also external obstacles that can be identified in all theoretical parts and in the qualitative survey.

As already mentioned, a trend towards professionalization can be seen in the field of mediation. Nevertheless, there are critics about standards of mediation trainings, according to the interviewed mediators. Mediation can still be performed by any professional in many countries. Often it is not a legally protected term of profession. The risk is that poorly performed mediations may harm the reputation of mediation in general.

Especially in Italy, the interviewed experts criticised that the Italian legislation is deficient in terms of training and selection procedures of mediators. ${ }^{26}$ In addition, the Italian criterion of territorial jurisdiction and of specific mediation centers $^{27}$ could be an obstacle to the spread of cross-border mediation, especially regarding co-mediation.

In a similar way, French experts criticise the lack of legislation in terms of training and selection processes and point out that only a few French mediators have experiences in transnational mediation or in matters of succession. Furthermore, especially in France, there are no institutional initiatives for the dissemination of mediation and for the gathering of statistical data on mediation. Apart from that, experts have pointed out that there are still major problems in terms of relations

22 See chapter 3.4.6: Preparation of cross-border succession mediation, preliminary talk with the parties.

23 See chapter 4.2:, SWOT Analysis (mediation in cross-border conflicts in succession matters): cooperation between professional groups.

24 See Chapter 3.4.2: Cross-border succession cases: specifics and challenges and chapter 3.4.6: Preparation of cross-border succession mediation.

25 For example, setting up the estate inventory, see chapter 3.4.5: Cross-border mediation: advantages and challenges, involve additional legal professionals.

26 See chapter 3.4.11: Legal framework on mediation: evaluation of the experts: Italy.

27 See chapter 2.1.4: Mediation system in Italy: Main features. 
between mediators and conciliators but also between family mediators and other mediators. Consequently, such factors weaken the position of mediation, also in cross-border conflicts in succession matters.

In the case of Germany, certified mediators need to take part in a 120-hour training course in order to be able to call themselves certified. This relatively low minimal requirement can turn out to be a threat to quality standards, some of the interviewed mediators noted. ${ }^{28}$

Also, interviewed Polish mediators asked for a coherent training and certification system. ${ }^{29}$ Conversely, Swedish mediators consider the listing of mediators by Swedish courts as problematic; accordingly, there are no quality standards about their training and information provided by them are not evaluated or verified. ${ }^{30}$

The general state of institutionalization of mediation that had been highlighted as a strength can be regarded as a threat at the same time, as can be derived from several arguments.

In Sweden, where the system of free of charge court-based mediation has already been established and judges perform mediations themselves, this turns out as a disadvantage for independent mediators since it poses an obstacle for out-ofcourt mediations. People may be less inclined to use external conflict resolution methods even though they might be more appropriate. Another special feature applying to Sweden is that mediation is commonly considered not to take more than one day, which raises questions about time and quality of such a process. ${ }^{31}$ Considering the situation in Sweden, the theoretical reports state that out-ofcourt mediation is not financed by the court.

From a French legal perspective, it can be seen as problematic that the costs of mediation are poorly regulated and can be freely determined by the individual mediators. Consequently, this non-transparency and disparity hampers procedures and makes it more difficult to conform with other systems such as the Italian one for instance.

Unlike in Italy, in Germany there is no obligation to consider or to perform mediation before starting a lawsuit. German mediation law provides that the procedure is absolutely voluntary. Mediators act on a free market and as such do not compete with the court system. Consequently, it is not surprising that mediation is commonly not regarded as a legal service in Germany and is therefore not supported through a legal aid program. Some pilot projects were recently launched in order to evaluate the effects of assumption of costs for mediation in family matters. But the effects of these projects are still uncertain. ${ }^{32}$

In terms of threats to mediation in succession matters, interviewees stated that sometimes lawyers are not always in favour of mediation. ${ }^{33}$ That shows mediation proceedings are still not supported by lawyers and notaries as desired. These

See chapter 3.4.11: Legal framework on mediation: evaluation of the experts: Germany.

See chapter 3.4.11: Legal framework on mediation: evaluation of the experts: Poland.

See chapter 3.4.11: Legal framework on mediation: evaluation of the experts: Sweden.

See chapter 2.1.6: Mediation system in Sweden: Institutional incentive system.

See chapter 2.1.3: Mediation system in Germany.

See chapter 3.4.11: Legal framework on mediation: evaluation of the experts: Italy. 
issues can become a threat in that sense, that rivalries between all sides can have negative effects on the spread of mediation.

In the case of Austria, the peculiarity of the inheritance proceeding (Verlassenschaftsverfahren) is that notaries, in the function of court commissioners (Gerichtskommissär), conduct the whole proceeding. ${ }^{34}$ This poses another threat to mediation in cross-border succession cases, since there are high obstacles for (nonnotary) mediators to become involved in the process.

Especially in terms of mediation cases with cross-border links, several other obstacles become evident. Geographical distances make it more difficult to bring quarrelling parties to one table or hear witnesses, language barriers and cultural differences make cross-border mediation more difficult. Likewise, foreign correspondence, translations and travel distances significantly increase the mediators' workload for such mediations. ${ }^{35}$

\section{Conclusion}

Mediation has become established at a European Level: one can say that the European Mediation Directive has generally strengthened the position of mediation in the field of out-of-court conflict resolution. Mediation has been integrated into the legal systems of the European countries. Nevertheless, the systems of mediation still vary a lot between the member countries.

Through the analysis of the expert interviews it became apparent that mediation is yet not very common in the field of inheritance disputes. Procedural fears still exist, as well as a lack of trust and misunderstanding towards mediation. ${ }^{36}$ Hereditary matters are a highly regulated part of society that are treated by specialised lawyers and notaries, which in parts explains misperceptions and lack of recognition of mediation procedures by heirs. Only in Italy where an initial mediation session is obligatory, heirs are automatically confronted with the idea of mediation.

Yet, there are many advantages to resolve or even prevent a conflict especially in this complicated area. Concrete advantages of mediation especially in cross-border inheritance cases are:

- avoiding legal proceedings and saving time and cost;

- bringing conflict parties together and maintaining personal relationships;

- overcoming communication problems and cultural differences;

- finding consensual solutions on the basis of personal needs of each conflict party.

34 See chapter 2.2.1: Law of Succession in Austria.

35 See chapter 4.2: SWOT Analysis (mediation in cross-border conflicts in succession matters): Threats of mediation in cross-border inheritance conflicts.

36 See chapter 3.4.5: Cross-border mediation: advantages and challenges. 
On the occasion of the 10th anniversary of the Mediation Directive Guiseppe de Palo speaks in a briefing note of the 'mediation paradox', ${ }^{37}$ meaning that mediation is generally highly praised, but is only rarely applied. The FOMENTO research report can generally underline the thesis that mediation does have great advantages to overcome or avoid conflicts, but is as yet still not widely practiced. Regarding the effects of the Succession Regulation it can be said that the Regulation brought many deep changes (applicable law according to the habitual residence, choice of law, European Certificate of Succession) for succession cases with a cross-border dimension. However, the Regulation and its effects are still quite unknown among citizens. Some of the interviewed experts stated that an evaluation of the Succession Regulation may still be too early. They argued that they had not gained enough experience with cases falling in the scope of the Succession Regulation so far.

Last but not least, the interviewed experts within the study emphasized the significant advantages of a mediation in the forefront of a succession case. This 'premediation' can be seen as best way of conflict prevention in succession matters at all. Citizens but also lawyers should be better informed about this possible use of mediation.

Furthermore, there is a great need of more networks between lawyers, notaries, judges and mediators to improve cooperation between professional groups and across national borders.

\section{Further actions: European Conference and network of mediators}

To promote cooperation between mediators across borders and between mediators, lawyers and notaries, the FOMENTO project will hold a European Conference on Mediation in Cross-Border Succession Cases on June 26th 2019 in Leipzig (Germany). ${ }^{38}$ Workshops and lectures will be offered on the following topics:

- mediation in succession cases (specifics, techniques, methods);

- legal issues in cross-border succession cases (effects of Succession Regulation);

- cross-border mediation (specifics, intercultural issues);

- co-mediation in cross-border context (techniques, communication);

- online-mediation (tools, techniques, application).

During the conference it will be possible to meet interested and experienced mediators and lawyers specialized in the field of succession.

Furthermore, a network for European mediators will be built up. On the one hand this should help citizens to find a suitable mediator for their succession conflict. On the other hand, lawyers and mediators should easier get in contact with each Directive, 2018, www.europarl.europa.eu/RegData/etudes/BRIE/2018/608847/IPOL_BRI \%282018\%29608847_EN.pdf. 
other. The project partners of FOMENTO, like Steinbeis Beratungszentrum Wirtschaftsmediation (Germany) want to support this goal.

Serielijst SNAAR

1 